\title{
Nano graphite as additive in soybean oil
}

\author{
George Catalin Cristea, Cosmin Dima, Dumitru Dima, Constantin Georgescu, and Lorena \\ Deleanu* \\ Dunarea de Jos University, Galati, Romania
}

\begin{abstract}
Vegetable oil-based lubricants have several disadvantages as compared to mineral and synthetic ones, including low viscosity that not encourage the generation of a continuous film when the tribosystem runs, consequently, implying a mixt or boundary. This is why the additivation of such oils is of great interests for researchers, producers and users. This paper presents results of testing the soybean oil additivated with nano graphite $(0.25 \% \mathrm{wt}, 0.50 \% \mathrm{wt}$ and $1 \% \mathrm{wt})$ on a four ball machine. The friction coefficient is slightly increased for the additivated lubricants, but no evident dependency on concentration and test conditions was noticed. Supplementary tests will give the opportunity of a statistical approach of this parameter. Any concentration of nano graphite makes the wear parameter (wear scar diameter) to slightly increase as compared to the values obtained for the non-additivated soybean oil. The increase of the nano graphite concentration in this vegetable oil does not influence significantly the wear parameter, meaning that, at least for the tested regime, this is not an efficient anti-wear additive.
\end{abstract}

\section{Introduction}

A SWOT analysis of lubricants based on vegetable oils points out the non-polluting character and the renewable resources for these materials $[1,2]$ But vegetable oil-based lubricants have several disadvantages as compared to mineral and synthetic ones, including low viscosity that not encourage the generation of a continuous film when the tribosystem runs, consequently, implying a mixt or boundary lubrication. This is why the additivation of such vegetable oils is of great interests for researchers, producers and users.

Tang [3] presented a review of the mechanisms of friction reduction and anti-wear of nanoparticles in lubricants: rolling effect [4], protective film, mending effect and polishing effect.

Shahnazar et al. [5], based on Rudnick works [6, 7], presented a well-documented classification of nano additives in lubricants, those based on carbon being classified in four main allotropic classes: zero-dimensional (fullerene), one-dimensional (nanotubes, nanowires, nanorodes), two-dimensional (graphene), three-dimensional (graphite, nanosized diamonds). Graphite has been used as micro particles in lubricants but adding it at nano level could enhance the friction and wear performance of the tribosystem.

\footnotetext{
*Corresponding author: lorena.deleanu@ugal.ro
} 
Hwang [8] concluded that lubricants with nano additives improve the tribological behavior as compared to microaddition of the same base oils. The presence of nanoparticles between the frictional surfaces significantly reduced contact between the frictional plates by playing the effective role of ball bearings. Analyzing the influence of additive shape, the fiber-like nanoparticles agglomerated easier than spherical nanoparticles and thus, the dimensions of agglomerated fiber-like nanoparticles became larger than that of the lubricant film, resulting in an increase in surface roughness and inhibition of the inflow of lubricating oil at the inlet of the frictional surfaces.

Martorana et al. [9] reported that ethanol containing graphite for gear pump proved to be significantly resilience without undergoing scission and degradation during running, but without significantly increasing the viscosity of the lubricant.

Lee [10] studied the graphite as nano additive in a mineral transmission oil and concluded that graphite nanoparticles decreases the metal contact between sliding surfaces by acting as ball bearing spacers.

The four ball test allows for easy comparing the tribological characteristics of a lubricant [11], results given by Solea [12] for several vegetable oil (olive, rapeseed, corn and soybean] allowing for comparing their performance to the mineral and synthetic ones.

This paper aims to report the influence of nano graphite as additive in soybean oil on the tribological behavior of the formulated lubricants.

\section{Testing methodology and lubricants}

The lubricants formulated with soybean oil additivated and nano graphite in different concentrations $(0.25 \% \mathrm{wt}, 0.50 \% \mathrm{wt}$ and $1 \% \mathrm{wt})$ were tested on a four ball machine in order to evaluate the improvement that this recipe provides for lubricating characterization with the help of parameters as friction coefficient, wear scar diameter. Table 1 presents the typical composition of this oil [12].

The nano graphite was supplied by PlasmaChem and has the following characteristic [13] and was produced by chemical disintegration of graphite. The average particle radius is $400-$ $450 \mathrm{~nm}$.

Table 1. Typical Fat acid composition for the tested soybean oil

\begin{tabular}{|c|c|c|c|c|c|c|c|c|c|c|c|}
\hline Fat acid & C14:0 & C16:0 & C16:1 & C17:0 & C18:0 & C18:1 & C18:2 & C18:3 & C20:0 & C20:1 & C22:0 \\
\hline & 0.11 & 12.7 & 0.13 & 0.05 & 5.40 & 21.60 & 52.40 & 5.70 & 0.25 & 0.20 & 0.50 \\
\hline
\end{tabular}

Table 2. Chemical composition of the steel the balls are made of (wt $\%)$

\begin{tabular}{|c|c|c|c|c|c|c|}
\hline Element & C & Cr & Mn & Si & S & P \\
\hline Steel grade EN31 & 1.0 & 1.3 & 0.5 & 0.35 & 0.05 & 0.05 \\
\hline
\end{tabular}

The degumming and refining process of soybean oil is done at Prutul SA Galati and prevents oil to form gum deposit and to ferment [14].

The four-ball machine (in the "LubriTest" Laboratory of "Dunărea de Jos" University of Galati, was designed by Schaeffer for a maximum load of $6000 \mathrm{~N}$, in agreement with the new standard SR EN ISO 20623:2004. Petroleum and related products. Determination of the extreme-pressure and anti-wear properties of fluids. Four ball method (European conditions).

The test balls are lime polished, made of chrome alloyed steel balls (Table 2), having $12.7 \pm 0.0005 \mathrm{~mm}$ in diameter, with $64-66 \mathrm{HRC}$ hardness. The sample oil volume required for each test was $8 \mathrm{ml} \pm 1 \mathrm{ml}$. The test method for investigating the lubricating capacity was EN ISO 20623:2003 Petroleum and related products - Determination of the extreme-pressure and anti-wear properties of fluids - four ball method. 
The test parameters were: three values for speed $(1000 \mathrm{rpm}, 1400 \mathrm{rpm}$ and $1800 \mathrm{rpm}$ corresponding to the following sliding speeds $0.383 \mathrm{~m} / \mathrm{s}, 0.537 \mathrm{~m} / \mathrm{s}$ and $0.691 \mathrm{~m} / \mathrm{s}$, respectively), three values for loading force $(100 \mathrm{~N}, 200 \mathrm{~N}$ and $300 \mathrm{~N})$, testing time 1 hour.

The issue that has to be solved with such anti-wear additive is its dispersion in oil. Thus, the authors, taking into account that the tested base oil is a mix of triglycerides of fat acids (Table 1) propose a method for obtaining a good dispersion. The formulated lubricants were obtained in a small quantity of $200 \mathrm{ml}$ each. The steps followed in this laboratory technology were:

- weighting the additive and the dispersing agent with an accuracy of $0.1 \mathrm{mg}$,

- mechanical mixing of additive and equal mass of guaiacol (supplied by Fluka Chemica), chemical formula being $\left.\mathrm{C}_{6} \mathrm{H}_{4}(\mathrm{OH}) \mathrm{OCH}\right)_{3}$ (2-methoxyphenol), for 20 minutes; this dispersing agent is compatible with both additive and vegetable oils,

- adding gradually the soybean oil, measured for getting $200 \mathrm{~g}$ of lubricant with the desired concentrations of additive,

- stirring with a magnetic homogenizing device for 1 hour,

- sonication + cooling of $200 \mathrm{~g}$ lubricant for 5 minutes with the help of sonicator Bandelin HD 3200 (Electronic GmbH \& KG Berlin); the lubricants is heating at approximately $70{ }^{\circ} \mathrm{C}$; the cooling time was 1 hour; this step sonication + cooling is repeated 5 times for obtaining a total sonication time of 60 minutes. The parameters of sonicating regime are: power 100 $\mathrm{W}$, frequency $20 \mathrm{kHz} \pm 500 \mathrm{~Hz}$, continuous regime.

\section{Results}

\subsection{Friction coefficient}

Being used as additive in oil, solid lubricants, including carbon-based materials as graphite, black carbon, even nano carbon tubes and onion-like graphite [15], considerably reduce friction between surfaces and wear where liquid lubricants do not perform desirably $[16,17]$. For the rolling effect, no chemical or mechanical reaction occurs, and the spherical nanoparticles are likely to roll between the friction surfaces and change the pure sliding friction to the mixed sliding-rolling friction.

The analysis of the friction coefficient (COF) takes into account the comment of professor Czichos [18] that distinguished, in general, four steps in the evolution in time of this tribological parameter. Graphics in Figures 2 to 4 are obtained by moving average of 200 successive values. The rate sampling for COF was 2 per second.

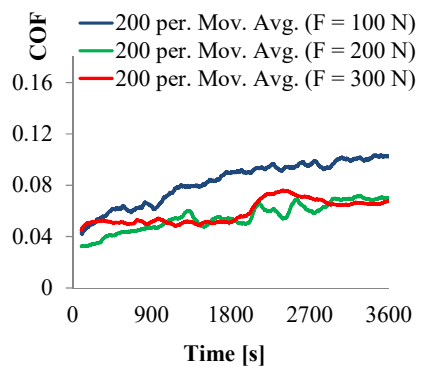

a) $1000 \mathrm{rpm}$

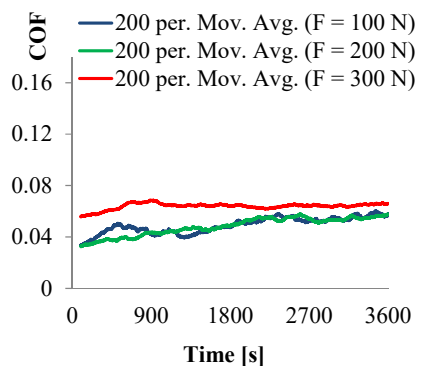

b) $1400 \mathrm{rpm}$

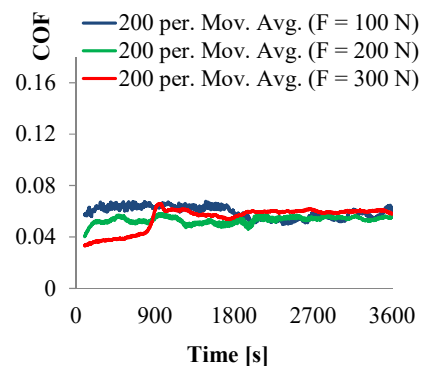

c) $1800 \mathrm{rpm}$

Fig. 1. Friction coefficient versus time for non-additivated soybean oil.

For the non-additivated soybean oil, the friction coefficient is less influenced by loading force at $1800 \mathrm{rpm}$ and an increasing evolution was obtained for the lowest values of speed 
and force $(100 \mathrm{~N})$. Stable period is obvious after several minutes but oscillations are more visible for low force and speed.

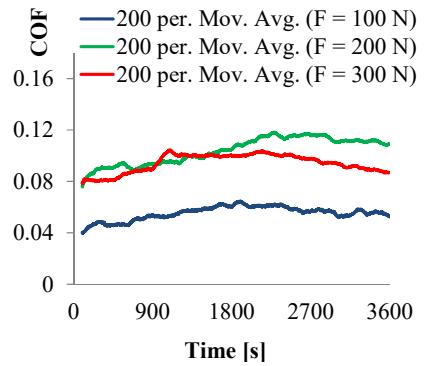

a) $1000 \mathrm{rpm}$

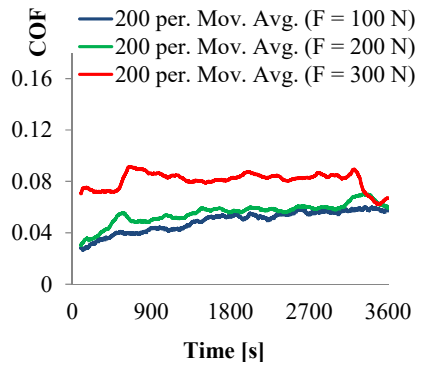

b) $1400 \mathrm{rpm}$

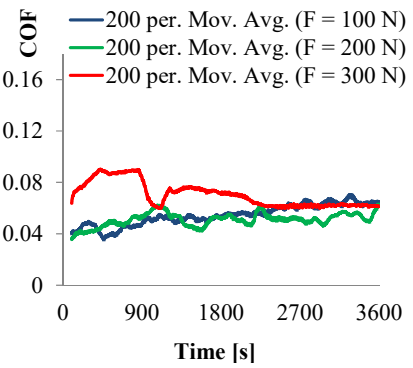

c) $1800 \mathrm{rpm}$

Fig. 2. Friction coefficient versus time for soybean oil $+0.25 \%$ nano graphite.

Adding $0.25 \%$ nano graphite in soyben oil makes the friction coefficient to slightly increase, especially for low speed (Figure 2). For a concentration of $0.5 \%$ additive, there were obtained higher values for $\mathrm{COF}$, especially for $\mathrm{F}=300 \mathrm{~N}$, suggesting a mixt regime and dragging the nanoparticles along the contact (Figure 3 ).

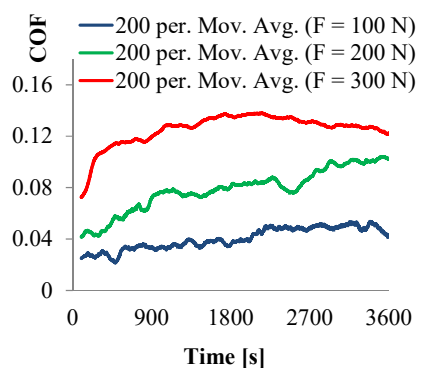

a) $1000 \mathrm{rpm}$

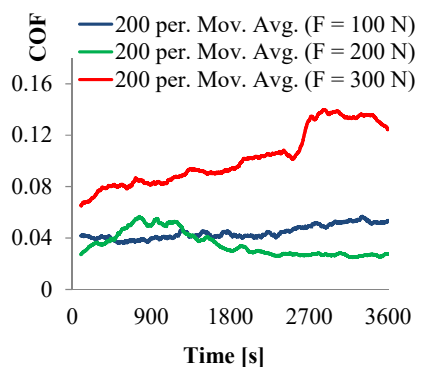

b) $1400 \mathrm{rpm}$

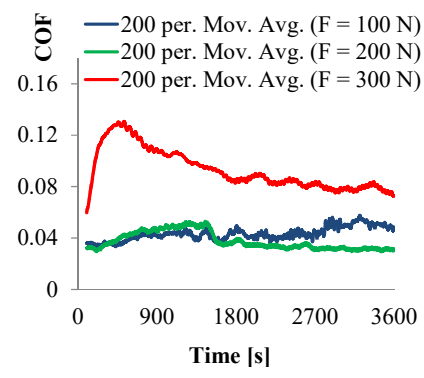

c) $1800 \mathrm{rpm}$

Fig. 3. Friction coefficient versus time for soybean oil $+0.5 \%$ nano graphite.

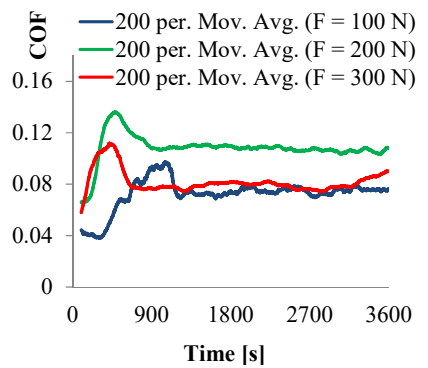

a) $1000 \mathrm{rpm}$

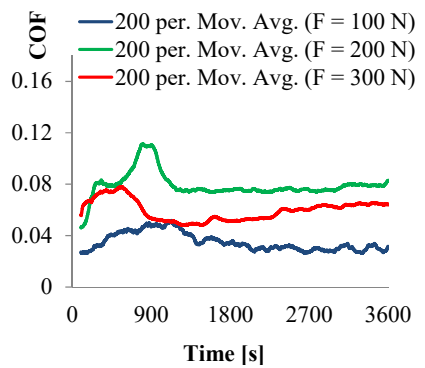

b) $1400 \mathrm{rpm}$

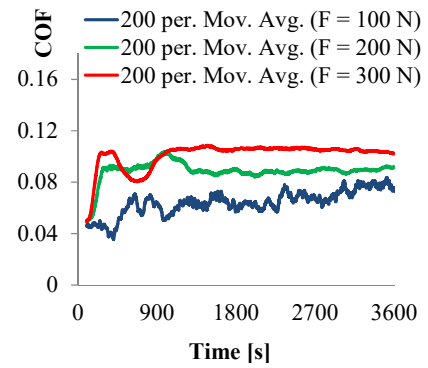

c) $1800 \mathrm{rpm}$

Fig. 4. Friction coefficient versus time for soybean oil $+1.0 \%$ nano graphite.

Except for several values of $\mathrm{COF}$, the average of this parameter has a similar evolution with the additive concentration for both 1 hour and the last 10 minutes of running, meaning a stable evolution of this parameter (Figure 5). Values are spread on larger interval for the concentration of $0.5 \%$ wt graphite and are closer for the neat oil and the lubricant with $1 \%$ wt. 

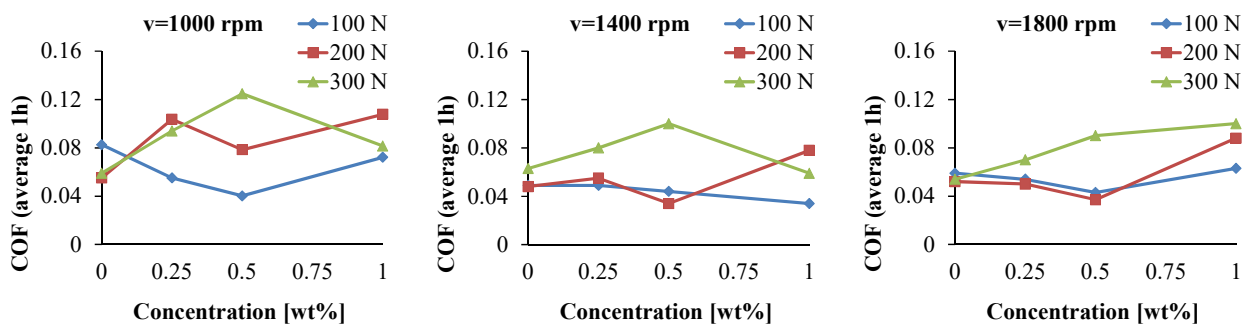

a) average values for $1 \mathrm{~h}$ of testing
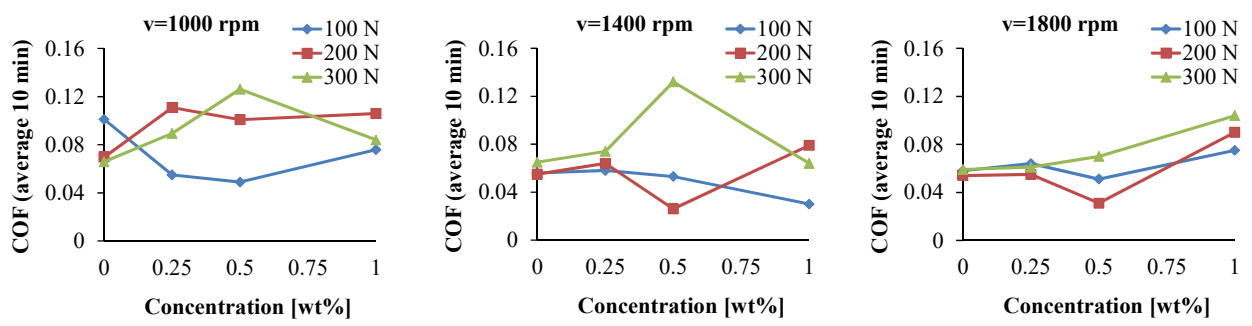

b) average values for the last 10 minutes of testing

Fig. 5. Influence of nano graphite concentration on the friction coefficient (COF).

\subsection{Wear}

An optical microscope was used to measure the wear scar diameters (WSD) (an example being given in Figure 6). Each value in Figure 7 is the average of six measurements. Each ball diameter was measured in the sliding direction and perpendicular to it.

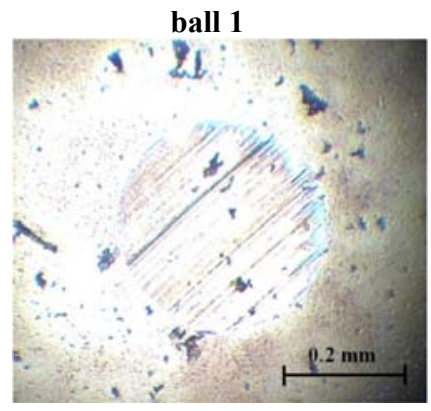

ball 2

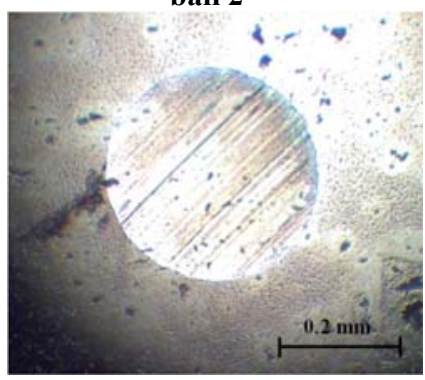

ball 3

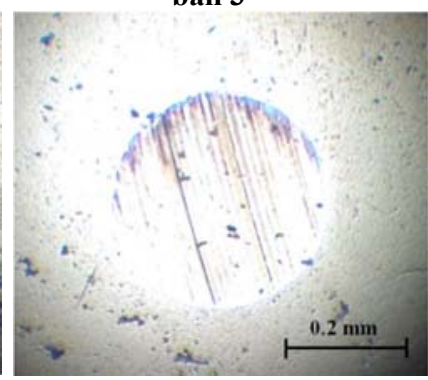

Fig. 6. WSD for soybean oil additivated with $1.0 \%$ wt nano graphite; test conditions: $100 \mathrm{~N}, 1000$ rpm, 1 hour.
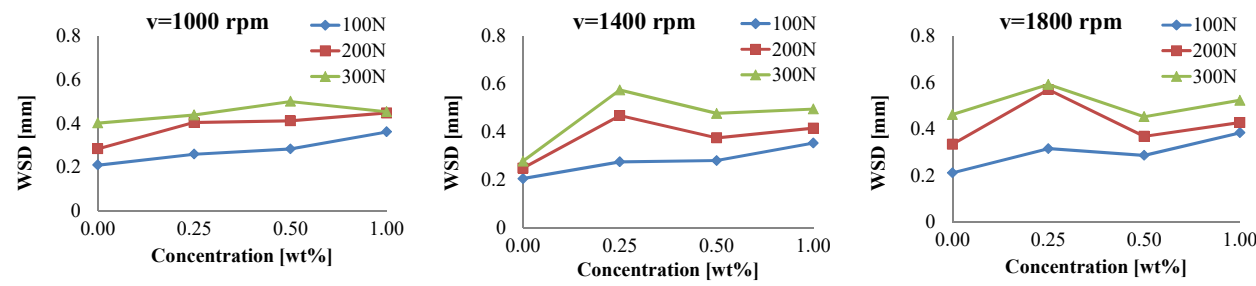

Fig. 7. Influence of additive concentration on the average value of WSD.

Adding nano graphite as additive in soybean oil, it is obvious that the wear is not reduced, but WSD seems to be less influenced by the testing regime. Further increase in additive concentration maintain the values of WSD in a narrow range (Figure 7), but for the 
investigated range of testing parameters (speed and normal force), there is not clear the tendency.

\section{Conclusions}

After testing the soybean oil additivated with nano graphite in different concentrations, the authors formulated the following conclusions.

The friction coefficient is slightly increased for the additivated lubricants, but no evident dependency on concentration and test conditions was noticed. Supplementary tests will give the opportunity of a statistical approach of this parameter.

Any concentration of nano graphite makes the wear parameter (wear scar diameter) to slightly increase as compared to the values obtained for the non-additivated soybean oil. The increase of the nano graphite concentration in this vegetable oil does not influence significantly the wear parameter, meaning that, at least for the tested regime, this is not an efficient anti-wear additive.

\section{References}

1. L. A. T. Honary, E. Richter, Biobased lubricants and greases technology and products (John Wiley \& Sons, 2011)

2. J. C. J. Bart, E. Gucciardi, S. Cavallaro, Biolubricants, (Woodhead Publishing Ltd, 2013)

3. Z. Tang, S. Li, Curr Opin Solid State Mater Sci, 18(3), 20 (2014)

4. Y. Y. Wu, W. C. Tsui, T. C. Liu, Wear, 262 (2007)

5. S. Shahnazar, S. Bagheri, S. B. A. Hamid, Intern. J. of Hydrogen Energy, 41, 17 (2016)

6. L. R. Rudnick, Natural oils as lubricants (CRC/Taylor \& Francis Group, 2006)

7. L.R. Rudnik, Lubricant Additives. Chemistry and Applications (Taylor\&Francis, 2009)

8. Y. Hwang, C. Lee, Y. Choi, S. Cheong, D. Kim, K. Lee et al., J Mech Sci Technol, 25(11), 5 (2011)

9. P. Martorana, I.S. Bayer, A. Steele, Industrial Eng Chem Res 49(22), 6 (2010)

10. J. Lee, S. Cho, Y. Hwang, C. Lee, S. H. Kim, Tribology Letters, 28(2) 6 (2007)

11. C. Spanu, M. Ripa, I. Stefanescu, L. Deleanu, The Annals of "Dunarea de Jos" University of Galati, Fascicle VIII, Tribology, 5 (2007)

12. L. C. Solea, PhD thesis, "Dunarea de Jos" University, Galati, (2013)

13. *** Nano materilas and related product, 1st ed. Catalogue PlasmaChem (2016)

14. E. M. J. Deffense, From organic chemistry to fat and oil chemistry (Oléagineux Corps Gras Lipides/OCL, 2009)

15. L. Joly-Pottuz, B. Vacher, N. Ohmae, J. M. Martin, T. Epicier, Tribol Lett, 30(1) 12 (2008)

16. P. Nagendramma, S. Kaul, Renewable and Sustainable Energy Reviews, 16, 11 (2012).

17. M. Gulzar, H. H. Masjuki, M. A. Kalam, M. Varman, N. W. M. Zulkifli, R. A. Mufti, R. Zahid, J Nanopart Res 18 (2016)

18. H. Czikos, Tribology - A System Approach to the Science and Technology of Friction, Lubrication and Wear (Elsevier, 1978) 